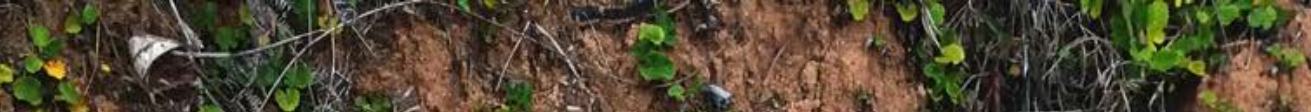

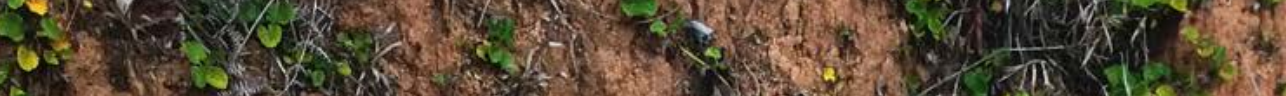

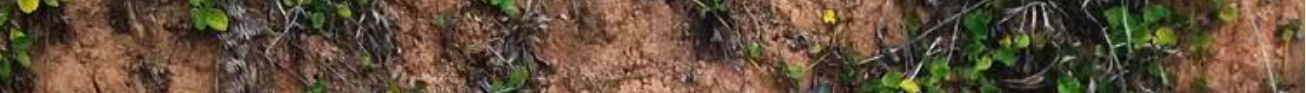

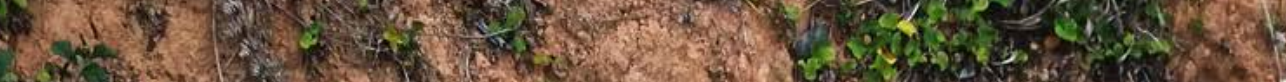

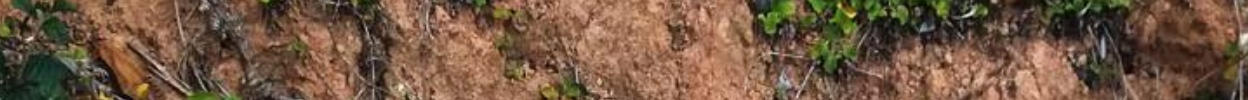

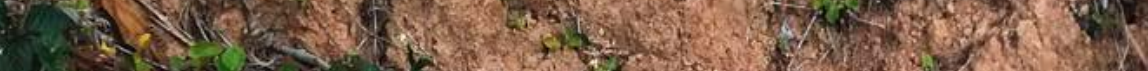

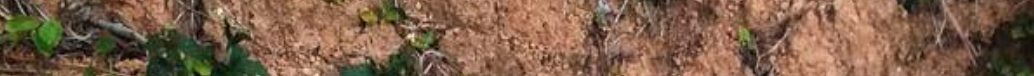
-

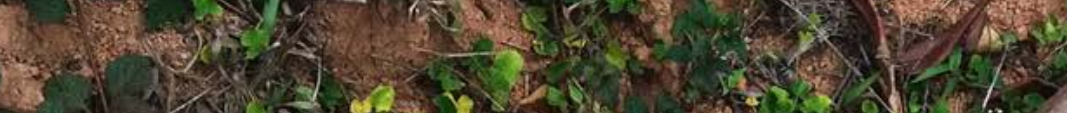

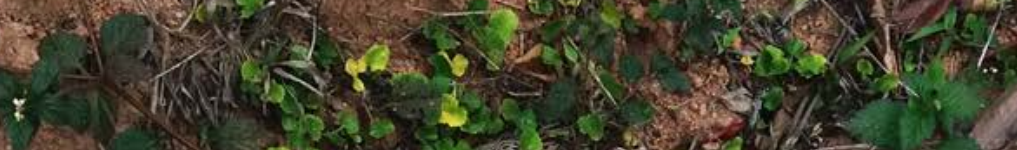

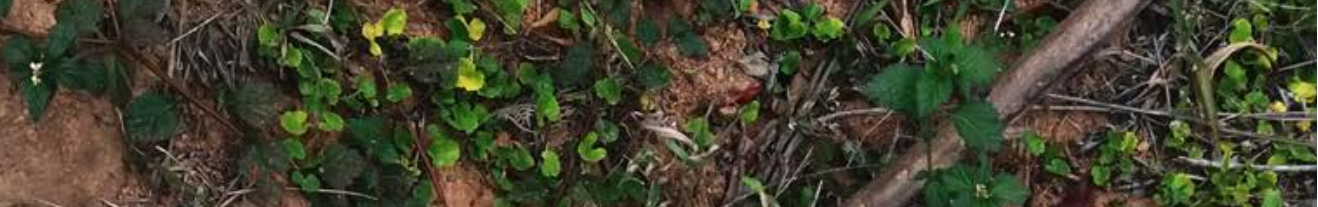

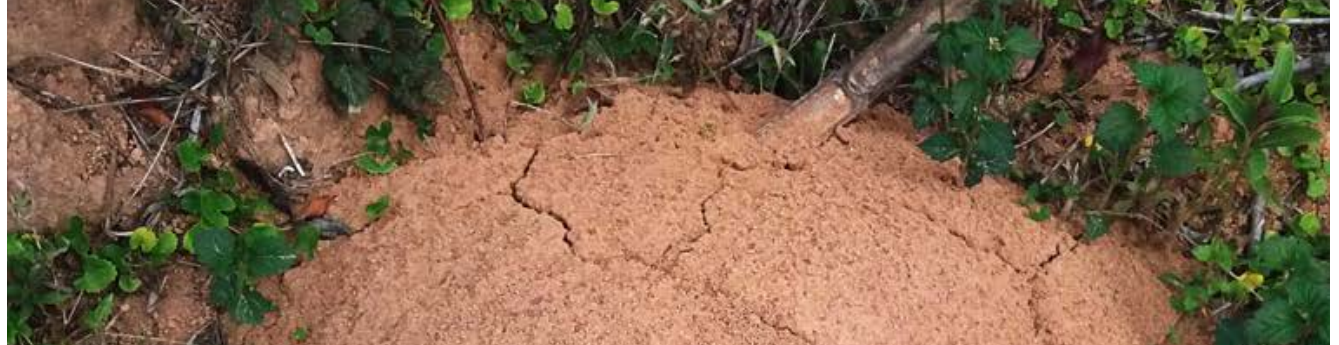

3.

10

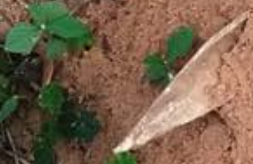

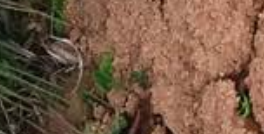

3.

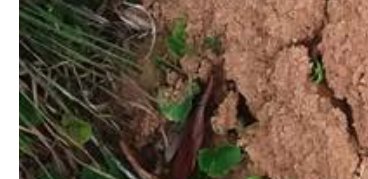

(f)

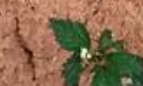

1.

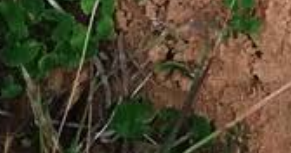

a.

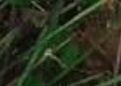

ais $4+2$

$8,2 x^{2}$

w.

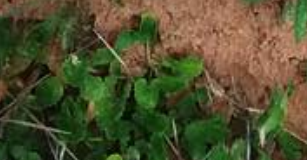

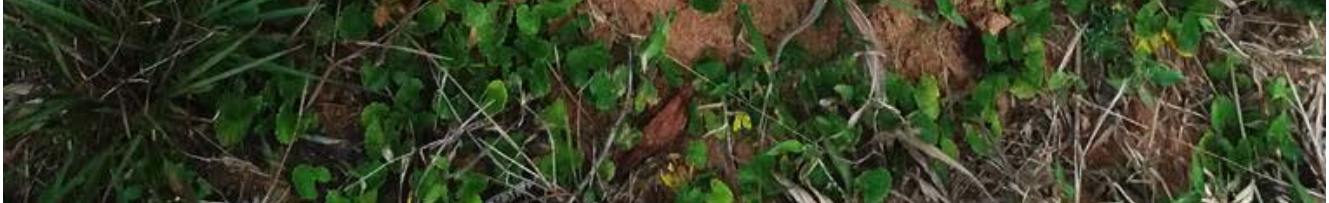

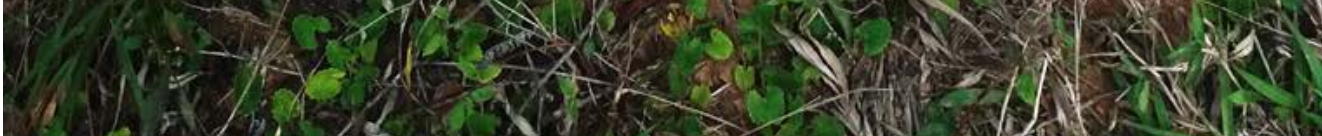

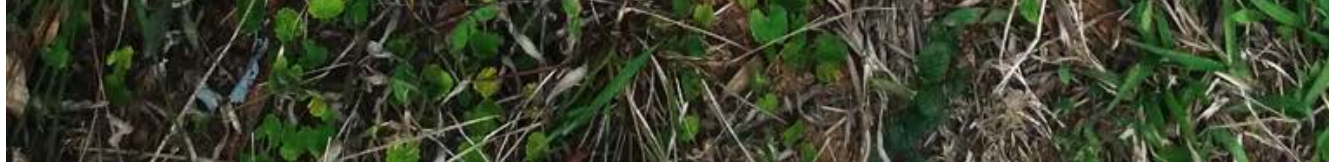




\section{O QUE NÃO É DE NINGUÉM}

\section{Leonardo Ventapane}

\section{imagem duplo mágica formigueiro geometria}

O texto, escrito em forma de ensaio, tangencia questões da fotografia, da imagem em movimento, da pintura e da escultura, e aborda o gesto criador contemporâneo pelo viés da inadequação, do duplo, do encantamento e do risco. Esses temas, de um modo ou de outro, se interpenetram e em meio a suas imagens rondam os desejos de impessoalidade e de não pertencimento.

WHAT DOESN'T BELONG TO ANYONE WHAT DOESN'T BELONG TO ANYONE | | Written as an essay, the text deals with creative issues that touch upon the photograph, moving image, painting and sculpture, and approach the artistic practice in contemporary visual arts, by the bias of inadequacy, childhood, enchantment and risk. These themes, somehow, interpenetrate themselves and invite the impersonality and the non-belonging to sniff around their images. I Image, double, magic, anthill, geometry.

\section{Para Robert Knievel e Ehrich Weiss}

Pode-se dizer que há uma escrita sobre a arte, uma escrita da arte, uma escrita na arte, uma escrita diante da arte ou uma escrita sob a arte. Mas também pode-se dizer que há uma arte sobre a escrita, uma arte da escrita, uma arte na escrita, uma arte diante da escrita ou uma arte sob a escrita.

Bernardo Ortiz ${ }^{1}$

And it is not surprising that the deepest problems are in fact not problems at all. Ludwig

Wittgenstein ${ }^{2}$

\section{Redemonho}

Eu queria ser dublê, como provavelmente outras crianças da minha época. Encantado mais pelo risco do que pela fama, como provavelmente outras crianças (da minha época). A cabeça agora diz: privilegiava a ideia de um duplo in(dis)pensavelmente anônimo e exposto a toda sorte de cicatrizes em nome do corpo de outro. Ou melhor, talvez melhor ainda seja compreender: nome como imagem (aquela nascida da excitação entre dois elementos). Em corpo do corpo de outro. Mas que corpo é esse, sem espessura? Mais 
do que seus feitos, a façanha do dublê é animar a coagulação daquilo que escapa da abertura entre um corpo outro e sua imagem (outra). Teria órgãos, Gilles? Mais para Artaud do que para Rimbaud. A alteridade também (se) machuca. Mesmo com toda dose de contrariedade e violência sobre as quais possa repousar, apaziguado, o encontro (de encontrar, do lat. in contrare) do sujeito consigo mesmo (ou consigo outro), ele, o encontro, marca a diferença entre o surpreender e o surpreenderSE, entre o expor e o expor-SE. Deslocamento do lugar do truque, da informação e do acúmulo para outro, da magia e do saber de experiência. ${ }^{3}$ "Aquilo que acontece" versus "aquilo que ME acontece". A reflexividade e a reflexão que o pronome impõe, condicionando toda experiência que verdadeiramente nos toca e nos atravessa a um tipo de coragem e de duplicidade (e, por que não dizer?, de cumplicidade), pedem uma pausa. Outro ritmo. Esvaziamento. O ator e seu doppleganger encenam a administração da matéria em um momento de crise. Algo em aceleração ameaça fugir do controle. Corta. É uma operação de superfície, mas não de "platitude"; epidérmica, mas incorpórea. Falamos de cortinas de fumaça, de tecidos de "aparecências" e de quase nenhuma opacidade. Apontam-se holofotes para a densidade de sujeitos que não cessam de inflamar o peso no/do mundo por uma entidade (na ausência de palavra ou imagem melhor) - não ator, não dublê - que, por baixo ou por fora, também os ilumina (refletindo), revelando a figura de um triângulo. Mínima geometria para a base de qualquer coisa que pretenda sustentar-se de pé. Vértices. Mas aqui a geometria não se deita em busca de estabilidade. A entidade (vértice) equilibra-se em ponta sobre si mesma, fundando (ou fundeando) essa trindade numa espécie de espetáculo articulado pelo encanto, circense (com tudo aquilo que do lado de fora e sem glamour algum sustenta o picadeiro), comprometido com a aleg(o)ria: um voo, uma queda, uma explosão, um atropelamento, sempre (em) outro plano... Não fosse ela, essa entidade-coágulo, e sua ludicidade irresponsável e fundamental, tudo ameaçaria desmoronar. No set, no filme, na vida (real)... E, ainda que em queda, as coisas ocupam seus devidos lugares. (As sutilezas que o encanto nos permite entrever, no entanto, nos avisam que o tombo para cima muitas vezes é o mais cruel: o entretenimento como ideia de arte e arte como ideia de entretenimento voam de encontro (in contrare) à mesma pilha de carros retorcidos/destorcidos na contemporaneidade). Enquanto isso, na aresta voltada para o alto do triângulo invertido, medem suas levezas o dublê (vértice) numa ponta e o ator (vértice) na outra. $\mathrm{O}$ primeiro, intimidade desconhecida, po(u)sado como um quasi-genius, a ponto de partir(-se). O segundo: "Sacrifício, quando é que se para de atuar?" Mas se a crença (ou a vontade) é a de se estar-com-o-diabo-no-corpo, como diriam os antigos, a entidade, devemos saber, foi quem soprou a Deleuze: "Jamais perca o concreto de vista" ${ }^{4}$ e, nesse sentido, sabe muito bem em qual cavalo apostar. Das pastagens extensivas do pensamento kinematográfico, o dublê faz ode à glória do (re)tirado, do (re)negado, do bastardo; engordando (n)a criação intensiva de um cubículo de tempo, como se jamais tivesse existido. $\mathrm{Ou}$ sempre. Mas será dele a carne mais macia? Excesso da atuação e da imaginação, agente de uma mise en abyme da própria ficção, fabulando pelo lado do meio, o dublê ensina que, como duplo, vale pela impessoalidade do terceiro, quarto, quinto... espectros a que dá ensejo. Seu mérito é engendrar, como um reflexo-sem-corpo numa fotografia de Brassaï, não exatamente uma imagem, mas um vácuo originante que reduplica, assinalando o vão entre tautologia e eternidade. Sombra-de-homemsem-sombra. Reflexo de vampiro. Selvagem, sua 
alma foi capturada pela câmera. Ou deixou-se capturar porque só ali, through-the-lenses, pode integralmente existir? Tem algo específico (mas também inominável) em relação à fotografia que parece (dis)simular a (dis)solução das hierarquias, para além da tensão imagem/referente. "Acho que, se eu estiver na presença da imagem", declarou Bacon, "não conseguirei me soltar tanto quanto se trabalhasse somente a partir da imagem fotográfica. (...) acho menos inibidor pintá-los de memória e de suas fotografias do que com eles sentados diante de mim". ${ }^{5}$ A palavra revela o que o olho do pintor já antecipou: não há mais corpo, mas "presença de imagem", que flutua igualmente a poucos passos da fotografia, da memória ou de sua própria pintura. Mas, ainda assim, presença perturbadora. Porque, afinal, voltemos à pergunta: que corpo é esse sem espessura? A carne retorna no corpo da tinta, mas o dublê, por favor, precisa sair de cena. Imagem como nome (aquele nascido da excitação entre dois elementos). Corta. Renata pinta postais. ${ }^{6}$ Velhos postais que nunca lhe foram endereçados, mas adquiridos aos lotes, em feiras de antiguidades. Não suas paisagens, mas os textos que trazem nas costas, se duplicam. Cada volta de letra, cada erro de grafia do remetente, cada elemento já impresso pela gráfica, cada pressão do carimbo da agência postal, cada mancha no papel imposta pela longa viagem na geografia e no tempo, tudo é retomado pelo plano de intimidade absoluta do óleo. Renata se faz, de uma só vez, remetente e destinatário, impressor e escritor, carteiro, voyeur, falsificadora, criadora... E se incluindo personagem dessa narrativa às avessas, Renata se retira. E retira também, desfazendo, os demais personagens de uma lenta comunicação já esquecida. Renata nos desfaz. Saímos de cena, todos, em prol de algo que a pintura sussurra com os/nos olhos, na violenta abertura escancarada pelo realismo excessivo, fotográfico, cegante até, de sua pintura. Vertigem.
A carne volta. Reencarna. Renata. Ainda que sem corpo algum. Corta. Ó, hesitante cisão entre a imagem-luz e o referente-luminoso! Aprende com a tinta a grandeza pastosa da diluição, da impureza, da submissão e da intempestividade, dos clarões e das sombras, das camadas e das superfícies! Toma para ti a tarefa de demover as ilusões e as agruras subsequentes advindas de uma fidelidade vendida em megapixel. Já sabemos que o instante decisivo da fotografia não é a fração de segundo do clique. Que nem a duração flexível do take, no vídeo ou no cinema, podem nos trazer alguma segurança... Mas ensina-nos, doce cisão, como num estampido, que o tiro não é o ápice da caçada! Que tudo aquilo que corre por fora, ou espreita, nos diz de um tempo outro. Groys diria mais simplesmente: "Art-based time, not time-based art". ${ }^{7}$ A última (e infinita) sequência do Steiner, de Herzog ${ }^{8}$ parece evocar, ainda que sem espelhos, o abismo de Owens. ${ }^{9}$ 25, 24, 23, 22, 21, 20, 19... frames per second: o voo en ralantissement da silhueta sobre a tela branca, após sua aterrissagem na neve ao longe, eleva a hesitação acima da imagem: era o entalhador quem performava como atleta-herói ou o atleta, um dublê de artesão? O corvo sorri. "Senti meu cavalo como meu corpo". ${ }^{10}$ Como o jagunço ou como o filósofo, podemos nos render: no final do dia, qual ator, qual artista, qual professor, não dirá a si mesmo "Eu não passo de um dublê!"? E qual dublê, secretamente, não dirá "Sou eu o grande protagonista dessa fantasia..."? Diante do redemonho, homem acidental, não é preciso decidir seu papel.

\section{Art(h)ur (ou "Um barco feito para virar")}

Há sempre susto. Ainda que a exposição ao desgaste já nos sirva como estratégia metodológica recorrente, toda experiência criadora traz o traço do espanto enfant. (Esquecer(-se) de Rimbaud). Na 
maioria das vezes, não há nada a ser preservado, de fato. Podemos morrer de gangrena na perna e depois seguir traficando armas de fogo no norte da África. Removo cuidadosamente uma vara de bambu (caída horizontalmente) do meio de (e em torno da qual cresceu) um formigueiro. Com um leve gesto, a pequena abóboda se rompe. Formigas se agitam num frenesi de túneis e minúsculos ovinhos brancos. Nowhere to go. Junto ao bambu, segue agarrado um pedaço da estrutura de barro (seco), como um último pedaço de picolé (molhado) preso ao palito num dia de verão. A vara, que já possuía uma ponta afiada, talhada provavelmente no momento do corte por um facão, pareceu-me, de repente, uma outra arma branca. Decido fincála, agora verticalmente, de volta no formigueiro. A-vara-e-seu-pedaço-de-formigueiro-suspensocom-formigas-de-cabeça-para-baixo-e-paracima. Prooooooonto... Sem resistência, a pedra fervilhante se fere suave, numa clareza medieval. Penso na aceleração do tempo e em Mies Van der Rohe. Penso em Arthur. Corta. Já no Rio, olho insistentemente para o conjunto recolhido na beira da praia que guardo como parte de meu tesouro, no parapeito da janela do estúdio. Uma moeda incrustada em um amontoado arenoso e ferroso e oxidado. Aspereza Van Dyck. A moeda jaz prateada e reluzente, quase metade para fora. O conjunto não é maior do que o polegar da minha mão e a crosta recobre o valor da moeda. Especulo. Certas vezes, sob certa luz que entra pela vidraça, tenho vontade de arrancar a moeda dali, minha pequena Excalibur, num gesto orgulhoso que não me fará rei de coisa nenhuma. Ou talvez, por Merlin, tomasse posse de alguma magia?! Caraoucoroa. Alan Moore acredita que a arte é o reduto da magia no mundo contemporâneo. Não é à toa que Matthew Barney tem Houdini entre seus ídolos. Confusos entre a imagem do objeto e o objeto da imagem, tem início a ilusão. "O que é que enferruja primeiro?
Quem é que se sufoca primeiro no oxigênio?", perguntava o mágico, a cada apresentação, à Dama do Lago, enquanto tentava, submerso, livrar-se de suas correntes. A-imagem-última-deum-corpo-imagem-acorrentado-e-submerso-e-desua-esposa-assistente-quebrando-o-tanque-devidro-como-combinado-depois-de-três-minutospassados-e-fazendo-escorrer-a-imagem-para-forade-si-mesma deve ter sido apoteótica. Chinese Water Torture Cell. ${ }^{11}$ Os chineses também o sabem: só o que é vivo amolece, afrouxa, murcha. Talvez não seja bem assim, mas em última instância, é a esse movimento que associamos a ideia de orgânico - a dizer: organismo! Do desenho ou do objeto que remetem às sinuosidades do que vive, senso comum, dizemos também "orgânico". No entanto, isso não é suficiente. Há uma distância clara entre a organicidade da forma - ou aquilo que nela assemelha organizar-se como se vivo fosse - e aquilo que insufla ao organismo vida. "Morrer é ficar duro como um cavalinho de carrossel", concluiu o filho de um amigo. A criança, melhor do que o adulto, talvez compreenda que a ideia de morte não reside na estaticidade do cavalo ou na rigidez do material com o qual o modelo de animal é confeccionado. Seria fazer pouco das muitas inteligências que atravessam a infância acreditar que essa conclusão é dada pela simples interrupção do movimento, pelo fato de o cavalo, "congelado", não poder galopar. Ela sabe: aquilo não é um cavalo. Ela sabe: ele não fará outros movimentos senão o de oscilar para cima e para baixo e girar perpetuamente, junto aos outros animais. Rodin ensinou que é a figuração das transformações do corpo entre um instante e outro, entre uma postura e outra ${ }^{12}$ - ou como mais precisamente nos diz Merleau-Ponty, "o corpo numa atitude que ele não teve em nenhum momento"13 - o que faz nascer da escultura a ilusão de movimento. Nesse sentido, a sensibilidade da criança toma a morte pelo cavalo 


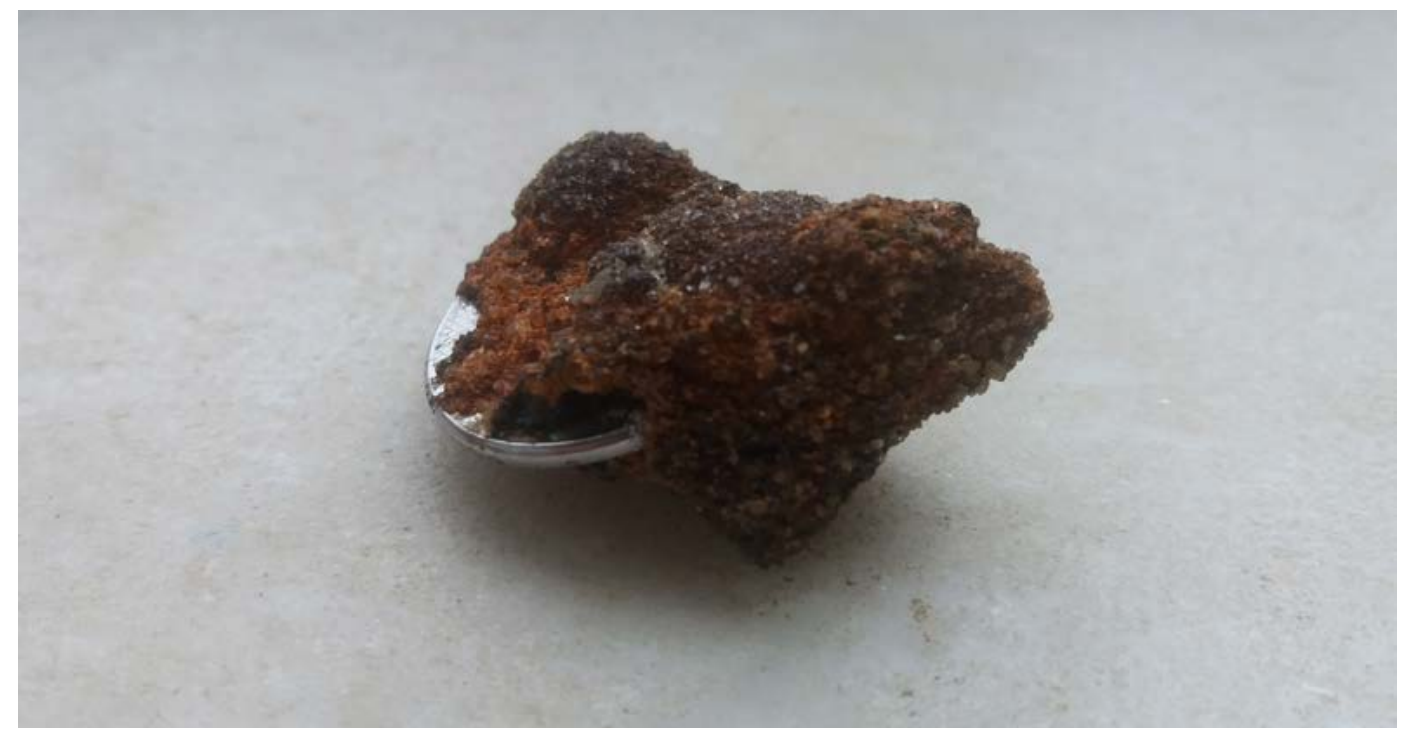

Foto: Leonardo Ventapane

pois não consegue compreender, acertadamente, como pôde aquele animal adotar aquela postura sem, utilizando o termo de Rodin, "metamorfose" alguma. Sem passagem. O cavalo de carrossel não morreu. Ele jamais esteve vivo! E é na tentativa de dar a ele suas fantasias que a criança parte em disparada, montada à espera de um relincho, um tropeço, um arrepio da crina, um breve espasmo muscular, um desmaio por exaustão, com o qual possa dizer: "Está morrendo!". É um movimento, um flerte com o fim, mas não a morte em si. Mórbido. Curiosa palavra que passa, também, de um estado a outro: doença, enfermidade, languidez, desequilíbrio psíquico, suavidade, delicadeza e maciez. Mais além, em italiano, mòrbido tende à doçura. Corta. Isabela diz Flácida, ${ }^{14}$ e busca encontrar, ou restaurar, na geometria uma ideia de corpo através das incertezas que, ao contrário do que possamos imaginar, o olhar científico lança sobre o mundo. Silicone, vidro, linha, luz, texturas e densidades dizem, em outra escala, de nossos movimentos pelos espaços não orgânicos que habitamos, mas também de um amolecimento da estrutura e dos materiais, arquitetônicos ou escultóricos, justamente pela incrustação desses espaços em nosso corpo. "Geometria Carnívora"15 é sua tentativa de conciliação. Corta. Outras vezes, a investigação é guiada por meio de um embate acentuadamente físico com o material, como se fosse urgente denunciar sua rigidez; como se fosse urgente viabilizar sua passagem, sua morte. Quando escolhi a hélice de três pás de um barco como objeto de partida para uma escultura, eu estava mais preocupado com a matéria do que exatamente com sua forma: ambicionava sua dissolução completa, dando origem à luminosa poça, ou mar de bronze. Foi somente trabalhando sobre ela, diante de sua dureza, de seu brilho e de sua forma "orgânica", tateando as dificuldades envolvidas nessa fantasia de derretimento, que me dei conta da riqueza desse objeto como obra de geometria, como um volume matemático. A 
(Whitechapel, documents of contemporary art). London: White Chapel/The MIT Press, 2010: 225.

3 Bondía, Jorge Larrosa. Notas sobre a experiência e o saber de experiência. Trad. João Wanderley Geraldi. Revista Brasileira de Educação [online]. n.19, 2002: 20-28.

4 Deleuze, Gilles. Carta-resposta. In Martin, JeanClet. La philosophie de Gilles Deleuze. Paris: Petite Bibliothèque Payot, 2005.

5 Sylvester, David. Entrevistas com Francis Bacon. Trad. Maria Teresa Resende Costa. 2 ed. São Paulo: Cosac Naify, 2007: 38.

6 Renata Nassur, pintora. Participou da edição 2018 da exposição Novíssimos, da Galeria Ibeu. Os trabalhos podem ser vistos em @renassur.

7 Groys, B. How to do time with art. In Godfrey, Mark; Biesenbach, Klaus Peter; Greenberg, Kerryn (ed.). Francis Alÿs: a story of deception. New York: Moma, 2010, p. 190-192.

8 Filme. O grande êxtase do entalhador Steiner (1974), de Werner Herzog.

9 Owens, Craig. Photography "en abyme". October, v. 5, 1978: 73-88. Disponível em: http:// www.jstor.org/stable/778646.

10 Rosa, João de Guimarães. Grande Sertão: Veredas. Biblioteca Luso-brasileira. Rio de Janeiro: Editora Nova Aguilar, 1994: 343. Disponível em: http://stoa.usp.br/carloshgn/files/-1/20292/ GrandeSertoVeredasGuimaresRosa.pdf.

11 Esse era o título da apresentação de Houdini, na qual era amarrado a correntes e cadeados e submerso em água em um grande tanque de vidro. Sua esposa e assistente de palco, Bess Houdini, estava autorizada a quebrar o tanque depois de três minutos, caso Houdini não conseguisse se soltar. Foi se apresentando na Chinese Water Torture Cell que o mágico morreu, em 31 de outubro de 1926.

12 Rodin, A. L'art; entretiens réunis par Paul Gsell. Paris: Ed. Bernard Grasset, 1911. Disponível em: https://archive.org/details/lartentretiensrO0rodiuoft.

13 Merleau-Ponty, Maurice. Textos selecionados. Seleção Marilena de Souza Chaui; tradução e notas Marilena de Souza Chaui, Pedro de Souza Moraes. São Paulo: Nova Cultural, 1989: 69. (Os pensadores).

14 Título da exposição de Isabela Roriz na galeria Alinalice, Rio de Janeiro, em maio de 2018.

15 Expressão utilizada pela artista em seu texto de apresentação, por ocasião da mesma exposição.

16 Artur Ávila, matemático brasileiro, ganhador da medalha Fields, comparável ao Prêmio Nobel em sua área, em 2014. Entrevista concedida ao jornalista Roberto D'Ávila. Disponível em: http:// g1.globo.com/globo-news/videos/t/todos-osvideos/v/roberto-davila-entrevista-o-premiadomatematico-brasileiro-artur-avila/5556582/.

17 Agamben, Giogio. Profanações. São Paulo: Boitempo, 2007: 22.

Leonardo Ventapane é professor adjunto da Escola de Belas Artes, atuando no curso de Comunicação Visual Design, no Programa de Pós-graduação em Artes Visuais e no Programa de Pós-graduação em Design. 